\title{
LIGHT GRAPHS IN PLANAR GRAPHS OF LARGE GIRTH
}

\author{
Peter Hudák, Mária Maceková \\ TOMÁŠ MADARAS \\ AND \\ PAVOL ŠIROCZKI \\ Institute of Mathematics \\ P.J. Šafárik University in Košice \\ Jesenná 5, 04001 Košice, Slovakia \\ e-mail: peter.hudak@student.upjs.sk \\ maria.macekova@student.upjs.sk \\ tomas.madaras@upjs.sk \\ siroczki@gmail.com
}

\begin{abstract}
A graph $H$ is defined to be light in a graph family $\mathcal{G}$ if there exist finite numbers $\varphi(H, \mathcal{G})$ and $w(H, \mathcal{G})$ such that each $G \in \mathcal{G}$ which contains $H$ as a subgraph, also contains its isomorphic copy $K$ with $\Delta_{G}(K) \leq \varphi(H, \mathcal{G})$ and $\sum_{x \in V(K)} \operatorname{deg}_{G}(x) \leq w(H, \mathcal{G})$. In this paper, we investigate light graphs in families of plane graphs of minimum degree 2 with prescribed girth and no adjacent 2-vertices, specifying several necessary conditions for their lightness and providing sharp bounds on $\varphi$ and $w$ for light $K_{1,3}$ and $C_{10}$.
\end{abstract}

Keywords: planar graph, girth, light graph.

2010 Mathematics Subject Classification: 05C10.

\section{REFERENCES}

[1] K. Appel and W. Haken, Every Planar Map is Four-Colorable (Providence, RI, American Mathematical Society, 1989).

doi: $10.1090 /$ conm/098

[2] O.V. Borodin, Solution of problems of Kotzig and Grünbaum concerning the isolation of cycles in planar graphs, Mat. Zametki 46(5) (1989) 9-12. 
[3] D.W. Cranston and D.B. West, A guide to the discharging method, arXiv:1306.4434 [math.CO] (2013).

[4] S. Jendrol' and M. Maceková, Describing short paths in plane graphs of girth at least 5, Discrete Math. 338 (2015) 149-158. doi:10.1016/j.disc.2014.09.014

[5] S. Jendrol', M. Maceková and R. Soták, Note on 3-paths in plane graphs of girth 4, Discrete Math. 338 (2015) 1643-1648. doi:/10.1016/j.disc.2015.04.011

[6] S. Jendrol', M. Maceková, M. Montassier and R. Soták, Unavoidable 3-paths in planar graphs of given girth, manuscript.

[7] S. Jendrol' and P.J. Owens, On light graphs in 3-connected plane graphs without triangular or quadrangular faces, Graphs Combin. 17 (2001) 659-680. doi:10.1007/s003730170007

[8] S. Jendrol' and H.-J. Voss, Light subgraphs of graphs embedded in the plane - A survey, Discrete Math. 313 (2013) 406-421. doi:10.1016/j.disc.2012.11.007

[9] A. Kotzig, Contribution to the theory of Eulerian polyhedra, Mat. Cas. SAV (Math. Slovaca) 5 (1955) 101-113.

[10] H. Lebesgue, Quelques conséquences simples de la formule d'Euler, J. Math. Pures Appl. 19 (1940) 27-43.

[11] N. Robertson, D.P. Sanders, P.D. Seymour and R. Thomas, The four-colour theorem, J. Combin. Theory Ser. B 70 (1997) 2-44.

doi:10.1006/jctb.1997.1750

[12] D.B. West, Introduction to Graph Theory (Prentice Hall, 2001).

Received 6 February 2015

Revised 8 June 2015

Accepted 8 June 2015 